\title{
Sovi \\ INTERNACIONAL \\ DE DESIGN \\ EDIÇÃO 2017 \\ Contribuições do Design de Serviços na Saúde Pública: a Unidade Basica de Saúde - UPA
}

\author{
Iona Chaves Alberto; \\ Johelma Pires Avelar; \\ Isabella Pontello Bahia
}

resumo:

No ambiente voltado para a assistência à saúde, questões pensadas sob a ótica do design se fazem necessárias. Na realidade da saúde pública, na cidade de Belo Horizonte/MG, a ótica do design de serviço pode resultar em melhorias consideráveis na assistência ao usuário e em ganhos na sua qualidade de vida. A proposta desse trabalho é apresentar conceitos sobre design, design de serviços e saúde, além de mostrar a etapa de acolhimento do serviço oferecido pelas Unidades De Pronto Atendimento - UPA's, e posteriormente, sugerir futuras possibilidades de atuação do designer por meio de ferramentas dos métodos de design de serviços. Esse trabalho apresenta etapas iniciais de pesquisas do projeto " Design de Serviços como ferramenta para o bem estar social em uma Unidade De Pronto Atendimento - UPA" que está em andamento na Escola de Design da Universidade do Estado de Minas Gerais - UEMG. O projeto procura contribuir para a melhoria da experiência do serviço na etapa de acolhimento das Unidades de Pronto Atendimento por meio dos conceitos, práticas e ferramentas do design de serviço. O projeto, devido ao forte caráter humano e, por conseguinte social, têm como referência os conceitos propostos por Manzini (2008), compreendendo, dessa forma, as relações ligadas ao uso sustentável, à inclusão e ao bem-estar. Consiste, também, na configuração de um documento com caráter teórico/diagnóstico com base nas ferramentas utilizadas na metodologia de design de serviços proposta por Stickdorn e Schneider (2010), observando, assim, os ambientes e suas relações. $O$ ambiente de análise é uma Unidade de pronto atendimento, na etapa de acolhimento. $O$ método de pesquisa utilizado para esse trabalho tem base na revisão de literatura voltada para a construção de repertório que permite o confronto das teorias e constatações sobre a problematização e o estabelecimento de critérios de juízo que ajudarão a nortear as prospecções com relação às discussões diante do tema. Como critério de escolha da UPA utilizou-se a proposta da realização de um Sorteio Aleatório Simples. Assim, todos os elementos da população terão as mesmas chances de fazer parte da amostra (MONTENEGRO, 1980). Assim, compreende-se, que o design de serviços pode colaborar para melhorias no sistema de saúde pública. Assim sendo, o projeto " Design de Serviços como ferramenta para o bem estar social em uma Unidade De Pronto Atendimento UPA" sugere estudar este contexto, diagnosticar dificuldades existentes na etapa de acolhimento das UPAs, e então propor soluções viáveis e coesas com a realidade deste serviço na etapa em questão.

palavras-chave:

Saúde; Design de Serviços; Acolhimento; Diagnóstico. 


\section{Introdução}

O design, segundo o Conselho Internacional de Design Industrial - ICSID (2013), consiste em uma atividade criativa que possui o objetivo de relacionar qualidades aos objetos, serviços, processos e aos sistemas relacionados a eles. Desta forma, pode ser compreendido como um fator determinante para a humanização dos processos tecnológicos, além da promoção de trocas culturais e econômicas entre atores sociais distintos.

Anos antes, Schneider (2010), professor de História da Cultura e do Design na Escola Superior de Berna e, também, presidente da Swiss Design Network, relata: ' O projeto de objetos de design é tanto uma prática social quanto a reflexão sobre essa prática. Tal discussão corrobora com a ideia do design enquanto [...] fator crucial de trocas culturais e econômicas" Ibid, (p.201).

De acordo com o SEBRAE (2016), em uma definição mais enxuta, o design é uma atividade projetual que preza por soluções criativas e está encarregada de planejar, criar e desenvolver produtos e serviços afim de atender as demandas do cliente conciliadas com as necessidades do mercado.

Em contrapartida, para Schneider e Stickdorn (2010), o design, independente da área, não se trata somente de um produto final e sim do processo realizado para que se chegue na solução adequada para o problema. Assim estes configuram o design como procedimento sistemático de identificação dos problemas, as pesquisas, análises, avaliações, sínteses, conceitualizações e a comunicação das soluções, são todos os processos que constituem o design.

Em suma, há um consenso sobre a essência do design enquanto uma atividade projetual utilizada para a resolução de problemas de forma criativa. É importante considerar também que tais diferenças referentes às perspectivas de cada autor a respeito do que é design, estão relacionadas ao propósito para o qual ele é utilizado. Este propósito pode variar desde a busca por uma pura inovação com a finalidade prioritariamente social, até a procura por uma inovação que atenda de forma efetiva um propósito pontual de mercado.

\subsection{Panorama histórico e novos cenários do design}

Alguns autores como Cardoso (2012) e Schneider (2010), entram em consenso em relação ao surgimento do design na época da Revolução Industrial. Pinheiro (2015), com base nos pensamentos de alguns líderes da escola Bauhaus, sugere que o design aparece no cenário da busca pela eficiência da produção industrial, aliada às artes e as disciplinas humanísticas.

$\mathrm{Na}$ análise de Escorel (2000 in MERINO; VIEIRA, 2012), o design como atividade em si, originou-se da necessidade da sociedade industrial de criar mecanismos que pudessem organizar o novo modo de produção de objetos e informações. Desta forma, a partir da revolução industrial, os objetos passaram a ser o foco das atividades projetuais (MARGOLIN, 2014), produzindo abordagens de viés industrial que culminavam no design bidimensional e tridimensional caracterizados pela materialidade dos produtos (SCHNEIDER, 2010).

Diante do contexto industrial que englobava desenvolvimento tecnológico e a produção em massa, os estudos em design e o mercado, apontavam a necessidade do direcionamento das habilidades dos designers não só para o desenvolvimento de projetos de produtos, mas também para as pesquisas voltadas para a consideração das necessidades humanas e as exigências de mercado de consumo. A partir daí, surge um novo olhar, mais cuidadoso para as questões metodológicas dos projetos de design (MARTINS; VAN DER LINDEN, 2012).

A explosão da " Era da Revolução digital não atingiu somente ao design, mas a todos os fatores que compõem o contexto da sociedade como: a economia, a política a sociedade e a cultura. Pois, à medida que o mundo virtual expande, a realidade parece desmanchar-se, torna-se imaterial (CARDOSO, 2012).

Segundo Ezio Manzini (2008), italiano idealizador do terceiro núcleo pioneiro na pesquisa sobre design de serviços, e Freire (2011), a realidade pós industrial resultou na mudança de enfoque mercadológico: da posse para o uso; da compra de produtos físicos para o uso de serviços. Mitchell (1998) ainda completa que a falta de estudo do contexto no qual os objetos estão inseridos agravou de forma significativa os problemas decorrentes da industrialização nas últimas décadas e portanto, a solução destes problemas está diretamente relacionadas ao direcionamento do pensamento do design para uma escala maior que o objeto. Desta forma, a tendência do design neste contexto seria o foco no 
intangível com soluções sistêmicas que levam em consideração tal estudo de contextos e as experiências do usuário.

Com essas mudanças de contexto, o leque de possibilidades de atuação e o caráter multidisciplinar do design aumentam incentivando cada vez mais o estudo destes contexto para a proposição de soluções projetuais cada vez mais assertivas no mercado em relação a produção, aceitação pelo público e consequentemente na venda dos produtos. Noções de marca, valor e associações ao que é simbólico também foram tomando forma neste contexto segundo Martins e Van Der Linden (2012).

Para Margolin (2014) diante de todos estes fatores que trazem inúmeras consequências para a sociedade atual e configuram, portanto, este contexto atual como sendo de alta complexidade, é exigido do designer, enquanto profissional que projeta coerência, segundo Bonsiepe (1984), uma perspectiva que abranja toda essa complexidade atual para a resolução de problemas complexos e portanto não é mais pertinente utilizar das divisões convencionais do design em diferentes áreas de atuação projetual pois para uma visão mais holística do processo, uma análise completa e um resultado projetual efetivo, é necessária a junção de todas as características individuais de cada design sendo ele gráfico, de produto ou de ambientes.

Segundo De Moraes (2010) tais problemas estão diretamente conectados aos novos desafios que constituem-se no cenário complexo do mundo atual e que estendem-se além do cenário moderno solido em que se desenvolveu a prática do design como era conhecida.

Para o design mais especificamente, a condição pós-moderna exacerba uma série de questionamentos e contradições que sempre estiveram latentes, mas cuja resolução antes era menos premente. Diante das profundas transformações ocasionadas pela adoção das tecnologias computacionais, por exemplo, a distinção tradicional entre design gráfico e design de produto tende a se tornar cada vez menos relevante (CARDOSO, 2013, p. 235).

Para Frascara (2002) o designer deve se preocupar mais com o contexto no qual os objetos e serviços são utilizados e com os efeitos dos mesmos na vida das pessoas do que com os objetos em si. Para alcançar tal objetivo o autor frisa a necessidade de entender as pessoas, a sociedade, o ambiente (ecossistema) além de buscar uma prática que seja interdisciplinar e, desta forma trocar o foco do design como sendo apenas a confecção de peças gráficas, produtos, sistemas e serviços.

Portanto, segundo Carlzon e Langerstrom (2005), a visão tradicional de design pautada em produtos não representa mais as forças socioeconômicas e ambientais atuantes devido à demanda atual de solução de problemas complexos de forma holística e completa. Buchanan (2001) complementa dizendo que nos dias de hoje, o design está focado na interação entre pessoas e tecnologias, e que por isso os produtos servem como plataformas para experiências, funcionalidades e ofertas de serviços.

\subsection{Design de Experiências}

A atividade do design, quando ligada ao projeto de objetos, também envolve o projeto de funções, contextos de uso, sistemas de organização e ambiente nos quais o mesmo estará inserido. Todos esses fatores contribuem para a experiência do usuário com aquele produto, o que o evidencia como um dos focos principais e centrais do processo de design. Além disso, como consequência deste foco no usuário, observa-se maior atenção para a qualidade da experiência a ser oferecida juntamente ao produto, o que reflete em maior conscientização e entendimento para com este processo projetual, e portanto, a tudo o que se refere ao projeto de design (FREIRE, 2009).

Para Pine, Gilmore (1998), a experiência é um processo decorrente da identificação de sensações ou conhecimentos dos usuários, sejam elas por elementos emocionais, físicos, intelectual ou espiritual proveniente do contato com diferentes elementos e contextos. Estes contatos podem apresentar níveis diferentes de interação e, de acordo com estes níveis, são formadas as impressões das interações provenientes dos aspectos de uso do produto em questão.

McLellan (2000) discute o design de experiência como sendo a criação de um espaço afetivo de contato com o usuário e de um contexto em questão com o propósito de atingir um determinado objetivo. Assim, é importante ressaltar a necessidade de um design coeso com a proposta e os 
elementos que compõe o projeto de forma a promover uma experiência assertiva e assim cativar o usuário.

Portanto, para que seja possível oferecer uma proposta de consumo ideal, o estudo do contexto no qual o objeto ou serviço está inserido, pode refletir em uma proposta de experiência de uso mais adequada ao conceito atrelado a esse produto. Essa maior atenção ao que se refere às características intangíveis do produto, narrada por Mitchell (1993) como necessidade atual de se pensar além do objeto, mostra novamente que a contribuição do designer pode ser por meio material (tangível), porém esta se encontra em segundo plano quando analisadas as demandas do mundo atual por um design intangível pois este abrange, desde de sistemas simples, aos mais complexos estabelecidos no contexto mundo contemporâneo.

\subsection{Relação do Designer com as pessoas na contemporaneidade}

$\mathrm{O}$ fato do design atualmente estar inserido em todas as áreas da sociedade, traz como consequência a responsabilidade do designer de, além de relacionar tais qualidades aos objetos, utilizar das ferramentas necessárias para a elaboração de produtos inovadores que agreguem o contexto em que os mesmos se inserem, pensando além do produto e levando em conta fatores como: a sustentabilidade do sistema e o bem-estar social (KÓRIA, 2010).

Nesta mesma linha, Ezio Manzini (2008), cita o designer como um ator social de grande importância por lidar com interações humanas cotidianas e seus artefatos, e por conseguinte, este profissional tem como dever, dentro do cenário mundial atual de degradação social e ambiental, oferecer novas soluções sustentáveis aos problemas do cotidiano.

Pode-se complementar, que o papel do designer é interpretar e conectar de forma holística e criativa as múltiplas concepções e perspectivas acerca dos problemas a serem solucionados. Para isso, o profissional que atua com o design deve levar em conta todo o contexto que se refere ao problema, a fim de, propor soluções adequadas, acessíveis, viáveis e pertinentes, visando o equilíbrio entre inovação, bem-estar e sustentabilidade. Além disso, como uma tarefa não menos importante, o designer deve promover a reflexão sobre questões contemporâneas e suas práticas colaborando para a construção e manutenção da sociedade.

Este viés mais humanizado do processo de design tem se tornado mais necessário em uma perspectiva em que o contexto atual no qual a humanidade está inserida é levado em conta. A busca cada vez maior pelo bem-estar vem crescendo juntamente ao ritmo da degradação ambiental e social do planeta e por isso, muitos designers têm estado atentos à algumas necessidades do ser humano e do planeta que sempre existiram mas que nos dias de hoje marcam forte presença.

Para que a dinâmica do processo seja melhor entendida, Manzini (2008) explica que em um mundo onde a degeneração da natureza pelo homem se desenvolve mais rápido do que a capacidade de resiliência da mesma, medidas precisam ser adotadas para que haja um desencadeamento de processos em prol da manutenção da sustentabilidade social e ambiental. Essas medidas requerem uma descontinuidade do sistema vigente, para a adoção de novas práticas e reversão da mentalidade e hábitos atuais dos indivíduos do planeta, a fim de preservá-lo.

$\mathrm{O}$ designer, como agente transformador e ator social, deve atuar em conjunto com a comunidade, a fim de reverter o consumo desenfreado que causa prejuízo a natureza e contribui para a intensificação de problemas sociais. Neste sentido, com diretrizes, orientações e planejamentos de sistemas, deve contribuir com à sociedade mostrando como os conceitos do design podem auxiliar nesta transformação na direção da sustentabilidade, e como tal transformação, pode trazer vantagens nos pontos de vista social e ambiental.

\section{Panorama social e mercadológico dos serviços}

$\mathrm{O}$ foco no imaterial passa a ser mais atrativo quando a sociedade se mostra saturada de bens físicos materiais (MANZINI, 2008). O contexto de vida das pessoas passa a ser caracterizado pela rapidez e flexibilidade, a posse de objetos físicos aparenta ser uma solução demasiadamente pesada e rígida o que, segundo o autor, intensifica e colabora para a inércia do sistema (RIFKIN, 2000)

De acordo com, Thackara (2008) o mundo, atualmente, se encontra em uma realidade na qual o bem-estar da população baseia-se cada vez menos em produtos físicos e mais na relação entre 
pessoas. $\mathrm{O}$ foco atual do design está no projeto de serviços e sistemas acompanhando o contexto atual e não mais no intangível. Entretanto, o autor não nega a importância dos objetos, que para ele, exercem um papel essencial para a movimentação da economia mundial. Além disso, é importante que os designers comecem a substituir os recursos físicos (tangíveis) por informação (intangível), levando em consideração que os objetos são meios para um fim e não fins em si mesmos.

Pinheiro (2015) corrobora com Thackara (2008) quando defende que os serviços não são totalmente intangíveis, e que se este fosse o caso não haveria forma de acessá-los. Para o autor, os produtos são formas de rastrear e de conseguir interagir com tais serviços, e desta forma, eles existem para garantir tal interação, além de fazer com que o usuário possa lembrar da experiência oferecida anteriormente.

Segundo o IBGE (Instituto Brasileiro de Geografia e Estatística) o setor de serviços é caracterizado por atividades bastante heterogêneas quanto ao porte das empresas, à remuneração média e à intensidade no uso das tecnologias. Nos últimos anos, foi analisado que as atividades do setor se destacam pelo dinamismo e pela crescente participação na economia brasileira IBGE (2017).

A qualidade do serviço se dá pela discrepância existente entre as expectativas e as percepções do usuário acerca do serviço usufruído. Isto é, quando as percepções desse usuário excedem suas expectativas durante e após o uso do serviço em questão, este é considerado um serviço de qualidade (ZEITHAML; PARASURAMAN; BERRY, 1985).

A performance de um serviço é dada pelo resultado da junção entre o comportamento do cliente, o processo executado e o comportamento do provedor do serviço. Por isso, os serviços são coproduzidos, sendo confeccionados a partir de uma rede de interações, o que significa que a qualidade dos mesmos depende de todos os atores e pontos de contato envolvidos no processo, e isso pode gerar uma constante variação nas performances (PINHEIRO, 2015).

O constante aprimoramento do serviço a partir de práticas que buscam entender e atualizar as percepções do usuário e que por isso procuram sempre alcançar um nível mais elevado de qualidade do serviço, é um ponto importante defendido por Oliva, Kallenberg (2003).

\subsection{Design de Serviços}

O design de serviços é uma área emergente que possui foco na criação de experiências que são cuidadosamente planejadas. Tais experiências, ainda segundo a definição, são resultado de diferentes combinações de mídias tangíveis e intangíveis.

Já para Buchanan (2009) o design de serviços pode ser entendido como o ato de projetar serviços estimulando e promovendo a participação efetiva das pessoas envolvidas naquele contexto a fim de promover benefícios entre as partes envolvidas no processo. Portanto, refere-se a uma atividade projetual de serviços em que há o intuito de agregar valor à marca. Além disso, sendo uma atividade de design, têm foco importante no processo e no usuário do serviço.

Zeithaml e Bitner (2003) consideram que o design thinking de serviços possui, portanto, um foco não em organizações, mas sim, em seres humanos e, desta forma, procura encontrar maneiras de promover a cocriação de valor a partir da interação entre organizações e stakeholders. Complementando, Sasser (1978) definiram o design de serviços como design gestão e melhoria do sistema de entrega de serviços, sendo o termo design utilizado para a descrição da elaboração de detalhes relacionados aos usuários, tecnologias, práticas e processos. Portanto, o design de serviços visa a obtenção de um certo nível de desempenho destes serviços, otimizando os custos e os recursos.

Holmlid (2009) defende que o design de serviços é uma disciplina que herdou diversas características provenientes do design de interação e por isso, possui uma relação estreita com o mesmo. Dentre essas características têm-se a aura colaborativa do design de serviços mais conhecida como co-criação, a relação do usuário com as interfaces de produtos e serviços e a noção de que o designer projeta ferramentas facilitadoras ao processo de uso.

Schneider e Stickdorn (2010) ainda complementam o conceito ao afirmarem sobre a importância em focar o processo projetual no usuário e assim, acompanhar suas mudanças. O processo de cocriação dos serviços ocorre em todas as etapas do projeto, inclusive quando este é entregue/consumido e sofre modificações e adaptações a partir do conhecimento das percepções do usuário e, por isso, as ferramentas de etnografia são importantes para o processo. 


\subsection{O usuário e a cocriação no design de serviços}

Os serviços são criados por meio da interação entre usuário e provedor do serviço e portanto o usuário é um agente importante no processo de design de serviços. A intenção inerente de um serviço é atender as necessidades do usuário e, como consequência, ser recomendado por este a outras pessoas com sinceridade (SCHNEIDER; STICKDORN, 2010).

Segundo Lucy Kimbell (2010, apud SCHNEIDER; STICKDORN, 2010, p. 48), o design thinking de serviços é focado não nas empresas, mas sim em seres humanos e por isso busca encontrar formas de orientar organizações e stakeholders a cocriarem valor. Este foco nos seres humanos levanta a necessidade do uso da etnografia como auxílio no processo empático do design de serviços.

Schneider e Stickdorn (2010) defendem que a etnografia auxilia neste processo permitir que a equipe envolvida no projeto trabalhe a partir da perspectiva do usuário, promovendo a criação de novos projetos destinados a questões relevantes das vidas cotidianas dos usuários. Os autores sugerem que os designers utilizem deste conhecimento nas fases de geração de ideias, desenvolvimento e implementações de conceitos do projeto.

Nesse momento surge, então, a necessidade de abordar o processo de cocriação que é para Schneider e Stickdorn (2010) um dos princípios do design de serviços.

Posicionar o usuário no centro deum processo de design de serviços pressupõe encarar a realidade de que, potencialmente, existia mais de um grupo de usuários, e que cada um dos grupos possui diferentes necessidades e expectativas. Além disso, para oferecer serviços também é preciso levar em consideração os diversos stakeholders, como o pessoal da linha de frente, funcionários de retaguarda e gestores além das interfaces não humanas, como máquinas de venda automática (" vending machines") ou sites na Internet. Assim, uma única proposição de serviços envolver uma variedade de atores e diferentes grupos de usuários, bem como diferentes funcionários e tipos de interface. Durante o processo de design de um serviço, precisamos envolver os usuários, bem como todos os outros stakeholders, na exploração e definição da proposição de serviços (SCHNEIDER; STICKDORN, 2010, p.40).

Buchanan (2009) defende que o design de serviços estimula a participação ativas das pessoas no processo e oferece a oportunidade das pessoas de agir.

\subsection{Ferramentas do design de serviços}

Estas ferramentas utilizadas pelo design de serviços, Stickdorn e Schneider (2010), são utilizadas com o propósito de conhecer de forma efetiva o usuário, os atores envolvidos no projeto, os recursos relacionados ao serviço e o processo em si.

Assim como em qualquer outro aspecto de um projeto de design de serviços, não existe uma maneira certa ou errada de empregar essas ferramentas. Um projeto bemsucedido envolve simplesmente encontrar uma combinação funcional capaz de conceituar, desenvolver e fazer protótipos das ideias utilizando um processo iterativo de melhoria gradual (STICKDORN; SCHNEIDER, 2010, p. 150).

A ferramenta de persona consiste na criação de perfis fictícios que representam um grupo específico de pessoas que possuem interesses comuns. Estes perfis são confeccionados a partir de um compilado de insights de pesquisa a respeito dos usuários do serviço. Esta ferramenta é utilizada com fim de oferecer diferentes perspectivas acerca de um serviço, além de promover maior aproximação entre o designers e o público alvo, facilitando o processo de empatia e gerando portanto maior compreensão do usuário do serviço. Esta aproximação permitirá que o projeto do serviço atenda de forma efetiva as necessidades do grupo de usuários do serviço em questão (SCHNEIDER; STICKDORN, 2010).

O mapa de stakeholders consiste na representação visual ou física dos variados públicos envolvidos no processo do serviço e das interações entre eles. Esta representação permite que as 
atividades destes grupos, que envolvem funcionários, clientes, organizações, entre outros, sejam analisadas e posteriormente mapeadas para evidenciar os interesses e necessidades dos mesmos. Este processo é realizado com o objetivo de otimizar de maneira eficaz os recursos e aumentar o grau de engajamento ao serviço (SCHNEIDER; STICKDORN, 2010).

O mapa de jornada do usuário é uma narrativa que detalha as interações do usuário com o serviço e as emoções e experiências que acompanham tais interações de modo acessível. Cada interação é considerada um ponto de contato, e portanto, é ordenada de forma coerente com as ações dos usuários dentro daquele serviço. Este mapa oferece para o projetista uma visualização vívida, dinâmica e estruturada da experiência do usuário com o serviço. (SCHNEIDER; STICKDORN, 2010).

Este panorama do serviço o qual o mapa de jornada do usuário oferece explicita fatores que possivelmente influenciam a experiência do cliente sendo construído a partir de sua perspectiva. Esse mapeamento permite identificar áreas problemáticas e oportunidades de inovação do projeto.

\section{Panorama sobre a Saúde}

A Organização Mundial de Saúde - OMS (1983) define saúde não apenas como a ausência de doença, mas como a situação de perfeito bem-estar físico, mental e social. Canguilhem (2006) compreende a saúde como um complexo conjunto, em que estão envolvidas as condições atuais e futuras, construída a partir de ações curativas e preventivas.

Tal pensamento vem de encontro com o texto da Lei $\mathrm{N}^{\circ} 8080$ (1990) que ressalta que a saúde é determinada por aspectos como a alimentação, o saneamento básico, as condições de moradia, atividade física e lazer, por exemplo. Ainda afirma que se incluem nesses aspectos todas as ações que se dispõem a garantir o bem-estar às pessoas e à coletividade.

A Constituição Federal de 1988, artigo 196, diz que: "A saúde é direito de todos e dever do Estado, garantido mediante políticas sociais e econômicas que visem à redução do risco de doença e de outros agravos e ao acesso universal e igualitário às ações e serviços para a promoção, proteção e recuperação".

Assim, a Declaração Universal de Direitos Humanos de 2009 corrobora com a constituição ao abordar no artigo XXV, parágrafo 1 que: " Todo ser humano tem direito a um padrão de vida capaz de assegurar-lhe, e a sua família, saúde e bem-estar, inclusive alimentação, vestuário, habitação, cuidados médicos e os serviços sociais indispensáveis, e direito à segurança em caso de desemprego, doença, invalidez, viuvez, velhice ou outros casos de perda dos meios de subsistência em circunstâncias fora de seu controle.'.

A fim de fazer cumprir os direitos dos cidadãos à saúde, o Governo Federal possui diversas iniciativas para a qualificação do serviço público de saúde como a implantação do Sistema Único de Saúde, Farmácia Popular, a Política Nacional de Promoção da Saúde entre outros programas que visam o estabelecimento de um sistema de saúde que atenda a população brasileira.

Segundo a pesquisa realizada em 2015 do Ministério da Saúde em parceria com o Instituto Brasileiro de Geografia e Estatística (IBGE), 71\% dos brasileiros utilizam o serviço público de saúde do país. Há a constatação por uma pesquisa realizada pelo Instituto Datafolha no estado de São Paulo que o tempo de espera médio para o atendimento no Serviço Único de Saúde (SUS) para 47\% dos entrevistados era de até 6 meses, com apenas $24 \%$ conseguindo obter atendimento em menos de um mês e $29 \%$ aguardando por um período maior que 6 meses. Dados do Tribunal de Contas da União (TCU) indicam também que $64 \%$ dos hospitais públicos brasileiros estão sempre com superlotação.

Estes dados mostram a deficiência do sistema público de saúde no Brasil e evidenciam o quadro de precariedade do atendimento aos enfermos nas cidades brasileiras.

\subsection{Unidade de Pronto Atendimento - UPA}

O Governo Federal, na tentativa de desafogar o fluxo cada vez maior dos hospitais e unidades do SUS em todo o país, implantou as Unidades de Pronto Atendimento, conhecidas como UPAs. As UPAs são uma estratégia da Política Nacional de Atenção às Urgências que auxilia o sistema único de saúde brasileiro. As Unidades de Pronto Atendimento - UPAs atuam ininterruptamente: acolhem pacientes, realizam triagem classificatória, resolvem quadros agudos e quando necessário encaminham o paciente para os hospitais. O funcionamento das UPA's conseguiu diminuir o fluxo intenso de pacientes de 
emergência nos hospitais, visto que a maioria desses pacientes acolhidos tem seus quadros resolvidos na própria Unidade (OLIVEIRTA et al., 2015).

Contudo, tanto diante de uma análise do panorama brasileiro, quanto mundial, oferecer saúde de qualidade ainda representa um grande desafio a ser vencido por todos os envolvidos nesse contexto. Essa ideia vem muitas vezes atrelada aos profissionais da saúde que são os que participam diretamente da assistência à população. No entanto, no entorno desses atendimentos, inúmeros outros profissionais trabalham para tornar esse trabalho o mais eficaz e efetivo possível.

Dessa forma, compreende-se, que dentro de um ambiente voltado para a promoção da saúde acontece, constantemente, a experiência de um serviço construído com base em relacionamentos entre os pacientes, funcionários e profissionais, além dos serviços por estes oferecidos. Portanto, segundo Cottan; Leadbeater (2004), membros do Design Council, o serviço de saúde deve ser estruturado de forma que envolva analistas, profissionais do setor de saúde e designer. Deve ter uma abordagem centrada no usuário, que envolva a comunidade, que pense em negócios e que, segundo Manzini (2008), promova o bem-estar, o uso sustentável e a inclusão social.

\subsection{Design de serviços na UPA: Oportunidade de atuação}

Quando se trata de saúde pública e emergencial, no Brasil, nota-se que o país enfrenta inúmeros impasses de difícil solução e requer que todos os profissionais envolvidos nesse sistema ofereçam sua colaboração para melhorar os indicadores de saúde dos cidadãos brasileiros. Posto este cenário, os profissionais da saúde apresentam um protagonismo neste tipo de serviço, entretanto, sabe-se que na área que permeia a assistência à saúde o envolvimento de diversos outros profissionais além de produtos, ambientes, serviços e interfaces que envolvem o processo deste serviço.

Em relação ao designer, é possível enxergar sua atuação na gestão de sistemas, em projetos de objetos, cenários, serviços como também, de interfaces, além, de sua importante contribuição em relação a humanização dos processos e tecnologias.

A interface Design e Saúde constitui hoje um tema internacional, seja no âmbito das discussões acadêmicas ou no campo da atuação profissional, portanto, essa proposta contribui com publicações que envolvam as duas áreas do conhecimento. Perpassa por uma perspectiva multidisciplinar comum tanto à saúde quanto ao design.

O olhar centrado no usuário em ambientes voltados para o cuidado à saúde pode gerar oportunidades para o desenvolvimento e melhoria da qualidade de vida da população, investindo assim na interação entre pontos que compõem o sistema de saúde e de quem dele usufruem. Dessa forma, permite contribuir na tentativa de se obter melhores resultados no que tange a promoção da saúde nos espaços das Unidades de Pronto Atendimento. Afinal, vale lembrar que são ambientes com funcionamento intenso e ininterrupto e são responsáveis por solucionar $97 \%$ dos casos em que recebem.

Diante de uma perspectiva de serviços, ambientes, produtos e informações em comunicação com a área da saúde e, em foco no setor de emergência, abre-se um grande potencial para a proposta do design de serviços, pois, esse método permite um olhar do profissional de design sobre toda a cadeia de ação e produção dos serviços em um ambiente de saúde.

\section{Metodologia}

A proposta desse trabalho é apresentar conceitos sobre design, design de serviços e saúde, além de mostrar a etapa de acolhimento do serviço de saúde oferecido pelas Unidade De Pronto Atendimento UPA's, na cidade de Belo Horizonte/MG e posteriormente, sugerir futuras possibilidades de atuação do designer por meio de ferramentas dos métodos de design de serviços. Esse trabalho apresenta etapas iniciais de pesquisas do projeto " Design de Serviços como ferramenta para o bem-estar social em uma Unidade De Pronto Atendimento - UPA" que está em andamento na Escola de Design do Universidade do Estado de Minas Gerais - UEMG.

O projeto procura contribuir para a melhoria da experiência do serviço na etapa de acolhimento das Unidades de Pronto Atendimento por meio dos conceitos, práticas e ferramentas do design de serviço. Devido ao forte caráter humano e, por conseguinte social, têm como referência os conceitos propostos por Manzini (2008), compreendendo, dessa forma, as relações ligadas ao uso 
sustentável, à inclusão e ao bem-estar. Consiste, também, na configuração de um documento com caráter teórico/diagnóstico com base nas ferramentas utilizadas na metodologia de design de serviços proposta por Stickdorn e Schneider (2010), observando, assim, os ambientes e suas relações. O ambiente de análise é uma Unidade de pronto atendimento, na etapa de acolhimento.

O método de pesquisa utilizado para esse trabalho tem base na revisão de literatura voltada para a construção de repertório que permite o confronto das teorias e constatações sobre a problematização e o estabelecimento de critérios de juízo que ajudarão a nortear as prospecções com relação às discussões diante do tema. A pesquisa apresenta, também base documental.

Como critério de escolha da UPA utilizou-se a proposta da realização de um Sorteio Aleatório Simples. Assim, todos os elementos da população terão as mesmas chances de fazer parte da amostra (MONTENEGRO, 1980).

\section{Considerações conclusivas}

O designer, de acordo com Bahiana (1998), é considerado o grande receptor de informações e possui a habilidade de integrar os objetivos de projeto às necessidades do usuário levando em conta os aspectos funcionais, ergonômicos e visuais dos projetos, buscando o conforto, a segurança e a satisfação de quem usufrui deles.

Estas habilidades podem ser usadas em prol da contribuição deste profissional para com a sociedade, elaborando projetos que visem solucionar problemas sociais e ambientais de baixa, média e alta complexidade. Andrews (2010) acredita que a atividade de design vai além da criação de bens de consumo e que o designer é um profissional capacitado para servir todas as áreas da sociedade.

A partir dos estudos proporcionados pela revisão da literatura, é possível compreender a capacidade do designer de serviços em contribuir com projetos para a comunidade mundial utilizando os cinco pilares do projeto de design thinking de serviços descritos por Schineider e Stickdorn (2010) que relacionam o foco no usuário, a cocriação do processo, a sequencialidade e fluidez das ações dentro do serviço, a procura de elementos que tornem o serviço evidente e a utilização da visão holística em todo o processo.

Compreende-se que o designer de serviço possui ferramentas e processos que podem auxiliar na resolução efetiva de problemas. A utilização da visão holística dos sistemas e a procura constante pela humanização dos processos que envolvem o projeto de design de serviços, fazem com que o designer consiga propor soluções mais coerentes com a realidade, que atendam com eficácia os interesses dos stakeholders e do consumidor.

O desafio do design na contemporaneidade é a exigência de uma visão alargada do projeto. $\mathrm{O}$ fenômeno da globalização e os avanços da tecnologia vem tornando o ofício do design mais complexo. o designer começa a ser um articulador e entender as experiências sensoriais e psicológicas como fatores para o desenvolvimento projetual (MORAES, 2010).

Manzini (2008) sugere que os designer podem ter um papel muito importante para a transição de mundo rumo a prática de inovações sociais. O mesmo enfatiza que apesar dos designers não possuírem meios de impor suas próprias visões aos outros, estes possuem, porém, instrumentos para operar sobre a qualidade das coisas e sua aceitabilidade.

Seu papel específico na transição que nos aguarda é oferecer novas soluções a problemas, sejam velhos ou novos, e propor seus cenários como tema em processos de discussão social, colaborando na construção de visões compartilhadas sobre futuros possíveis e sustentáveis (MANZINI, 2008, p.16).

Assim, compreende-se também que a cultura do design de serviços pode colaborar para que haja melhorias no sistema de saúde pública. Assim sendo, o projeto " Design de Serviços como ferramenta para o bem-estar social em uma Unidade De Pronto Atendimento - UPA" sugere a futura possibilidade de estudar este contexto, diagnosticar dificuldades existentes na etapa de acolhimento das UPAs, e então propor soluções viáveis e coesas com a realidade deste serviço.

O essencial para o projeto de serviços, é entender que o mais importante são as interligações entre os diversos momentos dos serviços e os comportamentos que conectam as pessoas. Reunir e administrar tais características holísticas e sistêmicas é uma postura propria do profissional de design, 
que deve buscar projetar as experiências que levarão à melhor experiência do usuário e melhor eficiência por parte do prestador do serviços (AVELAR;DIAS, 2015)

O designer pode, portanto, contribuir na construção das relações entre produto, serviços e estratégias; pode oferecer coerencia, pensar conexões que possibilitem a inovação para produtos, serviços, comunicações, ambientes e marcas. Nesse contexto, pode-se entender o design de serviços como a aplicação do estabelecido processo de design e das habilidades para o desenvolvimento de serviços na saúde.

\section{Contributions of Service Design in Public Health: The Basic Health Unit}

\section{Abstract:}

In the environment on health care, resistant subjects under optical design are required. In the reality of the public health, in the city of Belo Horizonte / MG, the design of the optical service can result in considerables improvements in the assistence to usuary and in gains in his quality of life. The propose of this work is to present concepts about design, services design and health, besides showing the Stage of reception of the service offered from unitys of Emergency Care Units, and after that, suggest future possibilities of designer's acting using tools of the method of service design. This work presents initial stages of researchs from the Project: "Service Design as a tool for social welfare in a Unit for Emergency Care Units (Unidade de Pronto Atendimento - UPA)" that is being made on the Design's Schools of the University of the Minas Gerais State. The project wants to Contribute to the improvement of the experience of the service in the stage of hosting the Emergency Care Units by means of concepts, pratical and tools of design of services. The project, due to the strong human and therefore social character, is based on the concepts proposed by Manzini (2008), thus understanding the relationships linked to sustainable use, inclusion and well-being. It also consists in the configuration of a theoretical / diagnostic document based on the tools used in the service design methodology proposed by Stickdorn and Schneider (2010), thus observing the environments and their relations. The analysis environment is Emergency Care Units, in the reception stage. The research method used for this work is based on a literature review aimed at the construction of a repertoire that allows the confrontation of theories and findings about the problematization and the establishment of criteria of judgment that will help to guide the prospecting in relation to the discussions before the theme. As a criterion for choosing the UPA, the proposal of a Simple Random Sortition was used. Thus, all elements of the population will have the same chances of being part of the sample (MONTENEGRO, 1980). Thus, it is understood that service design can contribute to improvements in the public health system. Thus, the project " Service Design as a tool for social welfare in a Emergency Care Units " suggests to study this context, diagnose existing difficulties in the stage of hosting the Emergency Care Units, and then propose feasible and cohesive solutions with The reality of this service in the stage in question.

Keywords: Healthcare; Service design; wellfare; diagnosis.

\section{Referências bibliográficas}

ANDREW, Kate. Design social: como entregar um impacto positive. In: SCHNEIDER, Jakob; STICKDORN, Marc. This is Service Design Thinking: Basics - Tools - Cases. Book Industry Services (BIS) - 2010. Hardcover

AVELAR, J. P.; DIAS, R. A. . Design de Serviços e a contribuição para o processo de inovação em empresas de micro e pequeno porte. In: Colóquio Internacional de Design. Belo Horizonte, 2015.

BAHIANA, Carlos. A importância do Design para sua empresa. CNI, COMPI, SENAI/DR-RJ, Brasília, DF. CNI 1998.

BONSIEPE, G. Design, Cultura E Sociedade. São Paulo: Blücher, 2011. 
BONSIEPE, G. Design: Do Material ao Digital. Tradução Cláudio Dutra. Florianópolis: FiES/IEL,1997.

BRASIL. Patrícia de Paula. Ministério da Saúde. PESQUISA NACIONAL DE SAÚDE: $71 \%$ dos brasileiros têm os serviços públicos de saúde como referência. 2015. Disponível em: <http://portalsaude.saude.gov.br/index.php/cidadao/principal/agencia-saude/17961-71-dosbrasileiros-tem-os-servicos-publicos-de-saude-como-referencia>. Acesso em: 26 jun. 2017.

BRASIL. Constituição (1988). Constituição da República Federativa do Brasil. Brasília, DF: Senado Federal: Centro Gráfico, 1988.

BUCHANAN, Richard. Four boundaries of service design. Pittsburg: Emerge, 2007. Disponível em: <http://designgeneralist.blogspot.com/2009/ 02/richard-buchanan-on-four-boundaries-of.html>. Acesso em: 4 set. 2011.

CANGUILHEM, Georges. 0 normal e o Patológico. $6^{a}$ edição, Rio de Janeiro, Forense Universitária, 2006.

CARDOSO, R. Design, Cultura Material e o Fetichismo Dos Objetos. Revista Arcos, Rio de Janeiro, v. 1, p. 14 - 39, 1998.

CARDOSO, Rafael. Uma introdução à história do design. São Paulo: Edgard

Blücher, 2004.

CARLZON, J.; LANGERSTROM, T. A Hora Da Verdade. Rio de Janeiro: Sextante,2005.

COTTAM, H.; LEADBEATER C. Health: Co-creating Services. London, Design Council, 2004.

DE MORAES, D. Metaprojeto: O Design Do Design. São Paulo: Blücher, 2010.

DIREITOS HUMANOS FUNDAMENTAIS: Comentários aos arts. $1 .^{\circ}$ a $15 .^{\circ}$ da Constituição Federal. São Paulo: Atlas, 1997. 308p.

FRASCARA, J. Diseño Gráfico Para La Gente: Comunicaciones De Massa Y

Cambio Social. Buenos Aires: Ediciones Infinito, 1997 apud FREIRE, K. M. Design De Serviços, Comunicação E Inovação Social: Um Estudo Sobre Serviços De Atenção Primária À Saúde. Tese de doutorado. PUC-Rio, Rio de Janeiro, 2011.

FREIRE, Karine. Reflexões sobre o conceito de design de experiências. In: Strategic Design Research Journal. V. 2(1), p. 37-44. Rio de Janeiro: Unisinos, 2009.

FREIRE, K. M.; DAMAZIO, V. Design de serviços: conceitos e reflexões sobre o futuro da disciplina. In: $9^{\circ}$ Congresso Brasileiro de Pesquisa e Desenvolvimento em Design. São Paulo, 2010.

HOLMLID, S. From interactions to service. In: S. M. M. koivisto (ed.) designing services with innovative methods. v. 1. Keuruu, Finland: University of Art and Design Helsinki, 2009.

HOLMLID, S.; EVENSON, S. 2008. Bringing Service Design to Service Sciences, Management and Engineering. In: B. HEFLEY; W. MURPHY, Service Science, Management and Engineering education for the 21st century. New York, Springer, p. 341-346.

ICSID. International Council of Societies of Industrial Design. About ICSID. Disponível em <http://www.icsid.org/about/about.htm\&gt:>. Acessado em: 10 de junho de 2016.

INSTITUTO BRASILEIRO DE GEOGRAFIA E ESTATÍSTICA - IBGE 2015.

Disponível em: <http://saladeimprensa.ibge.gov.br>. Acesso em: 20 de Jun. 2017.

KORIA, Mikko. O grande valor do design é poder criar um futuro melhor. In: Revista planeta. Ed.

459. Belo horizonte, 2010. Disponível em: <http://www.terra.com.br/revistaplaneta/edicoes/

459/artigo2065661.htm>. Acesso em: 7 out. 2011.

LANDIM, P.C. Design, Empresa, Sociedade. São Paulo: Cultura Acadêmica, 2010.

LOVELOCK, C.; WRIGHT, L. Serviços: marketing e gestão. São Paulo: Saraiva,2003. 
MANZINI, E. Design para a inovação social e sustentabilidade. Cadernos do Grupo de Altos Estudos, Programa de Engenharia de Produção da Coppe/UFRJ, Rio de Janeiro, vol. I 2008. Disponível em: < http://migre.me/rwrX1> Acesso em: 24 de agosto de 2015

MANZINI, E; VEZZOLI, C. O desenvolvimento de produtos sustentáveis. São Paulo: EDUSP, 2002.

MARGOLIN, V. Políticas Do Artificial: Ensaios E Estudos Sobre Design. Rio de Janeiro: Record, 2014.

MARTINS, R. F. F; VAN DER LINDEN, J.C.S. (Org.). Pelos Caminhos Do Design: Metodologia De Projeto. Londrina: EDUEL, 2012.

MCLELLAN, H. 2000. Experience design. CyberPsychology \& Behavior, 3(1):59-69

MERINO, G.; VIEIRA, M. L. H. O Design E Seus Desdobramentos. In: MARTINS, R. F. F; VAN DER LINDEN, J. C. S. (Org.). Pelos Caminhos Do Design: Metodologia De Projeto. Londrina: EDUEL, 2012, p. 175 - 222.

MONTENEGRO, Eduardo J. S. - Estatística programada passo à passo - volume 5 . Centrais Impressoras Brasileiras Ltda, 1980.

MV (Porto Alegre). Mv. Alguns dados sobre a saúde pública brasileira em que você precisa ficar de olho. 2014. Disponível em: <http://www.mv.com.br/pt/blog/alguns-dados-sobre-a-saudepublica-brasileira-em-que-voce-precisa-ficar-de-olho>. Acesso em: 26 jun. 2017.

OLIVA, R.; KALLENBERG, R. Managing transition from products to services. In: International Journal of Service Industry Management, v. 14, n. 2, p. 160-72, 2003.

OLIVEIRTA et al. Unidade de pronto atendimento - upa 24h: percepção da enfermagem. Texto Contexto Enferm, Florianópolis, 2015 Jan-Mar; 24(1): 238-44.

PINE, J.; GILMORE, J. H. Welcome to the experience economy. In: Harvard Business review. Boston: Harvard business school press, 76(4), p. 97-105, 1999.

PINHEIRO, T. D. The Service Startup: Inovação E Empreendedorismo Através Do Design Thinking. Rio de Janeiro, RJ: Alta Books, 2015.

PINHEIRO, T. D.; ALT, L. Design Thinking Brasil: Empatia, Colaboração E Experimentação Para Pessoas, Negócios E Sociedades. Rio de Janeiro: Elsevier, 2011.

SCHNEIDER, B. Design - Uma Introdução: O Design No Contexto Social, Cultural E Econômico. Tradução Sonali Bertuol, George Bernard Sperber. São Paulo: Editora Blücher, 2010.

Serviço BRASILEIRO de Apoio Às Micro e Pequenas Empresas. Design para todas as empresas: $O$ que é design. Brasília, 2012. Disponível em:

<https://www.sebrae.com.br/sites/PortalSebrae/artigos/o-que-e-design-e-o-que-ele-pode-fazer-pelasua-empresa,c636797d9ed77410VgnVCM1000003b74010aRCRD >. Acesso em: 15 jun. 2017.

STICKDORN, M.; SCHNEIDER, J. (Ed.). This Is Service Design Thinking: Basics,Tools, Cases. The Netherlands: BIS Publishers, 2010.

TACKARA, J. Plano B. O Design E As Alternativas Viáveis Em Um Mundo

Complexo. São Paulo: Saraiva: Versar, 2008.

The Compenhagen Institute of Interection Design (2008). What is Service Design? Disponível em <http://ciid.dk/syposium/sds/> Acessado em 10 de Agosto de 2010 apud STICKDORN, M.;

SCHNEIDER, J. (Ed.). This Is Service Design Thinking: Basics,Tools, Cases. The Netherlands: BIS Publishers, 2010.

WALKER, Richard (1985) "Is there a service economy?" Science and Society, vol. 49, no 1: 42-83.

YIN, Robert K. Estudo de Caso: planejamento e métodos. Porto Alegre: Bookman, 2001.

ZEITHAML, A. Z.; BITNER, M. J.; GREMLER, D. D. Marketing De Serviços: A

Empresa Com Foco No Cliente. 6. Ed. Porto Alegra, AMGH, 2014. 
ZEITHAML, V.A; PARASURAMAN, A; BERRY L. L. A Conceptual Model of Service Quality and Its Implications for Future Research. In: Journal of Marketing, V. 49, p. 41-50. New York: KenanFlagler bussiness schooll, 1985. 